\title{
Safety Cognitive Concept and Countermeasure Analysis for Petrochemical Industry
}

\author{
Mu Shan-Jun, Shi Hong-Xun, Wang Xiu-Xiang, \\ Zhang Xiao-Hua and Bian Min \\ China Petroleum \& Chemical Corporation \\ Qingdao Safety Engineering Institute; Qingdao Shandong \\ China
}

\section{Introduction}

In recent years, we collect a large number of accidents about the petroleum and petrochemical enterprise, summarized the data analysis shows that, along with the progress of science and technology, the improvement of technical equipment, petroleum and petrochemical enterprise in essence safety equipment has made rapid progress, but also see the man-made accidents still occur frequently, makes the enterprise safety production situation facing new challenges. In daily work, employees why always there will be some unsafe behavior, the main reason is enterprise managers in the safety cognition concept is still not aware of the employee behavior of the importance of safety, thus let employees formed "see be used to, dry to, used to" idea, the idea for a good safe for behavior is an advantage, but for unsafe behavior as it may cause an accident. So from safety cognition concept to looking for reasons of the occurrence unsafe behavior, thus looking for breach in behavior safety management, through the application of behavior safety management tools, regulate employee behavior of work.

\section{Widespread safety cognitive concept}

Thought Analysis of petroleum and petrochemical enterprise field work activities, observe homework personnel work behavior and interview with the staff, using the research methods of system theory, research and get enterprise employees and managers widespread security cognitive concept.

Through the analysis of the safety of the employees and managers cognitive concept, we find inconsistency in the enterprise employees and managers. From the two aspects to this paper discusses enterprise employees and managers of the safety cognitive concept.

1. Employees of the cognitive concept generally

In the enterprise, the staffs exist in the following cognition about unsafe behavior :

- Unsafe behavior can improve the work efficiency.

- Unsafe behavior may not cause an accident.

- If know accident, or should be safety work. 
Due to the shortcut and less effort to finish the job is the instinct of a man. In the work it will often be not according to procedures system operating practices, this operations mostly are unsafe behavior. In the process of operation, the unsafe behavior of the employees on one hand is that the employees don't by the operation regulation of generation for the saves time and effort. On the other hand may be produce the unsafe behavior that due to the managers blind pursue assignments, ignore security operations etc.Once the accident happened, safety awareness of employees will have been strengthened. For the management of the unreasonable requirement they will also put forward some suggestions, but improved safety awareness will fade with time passing by (Fig 1).

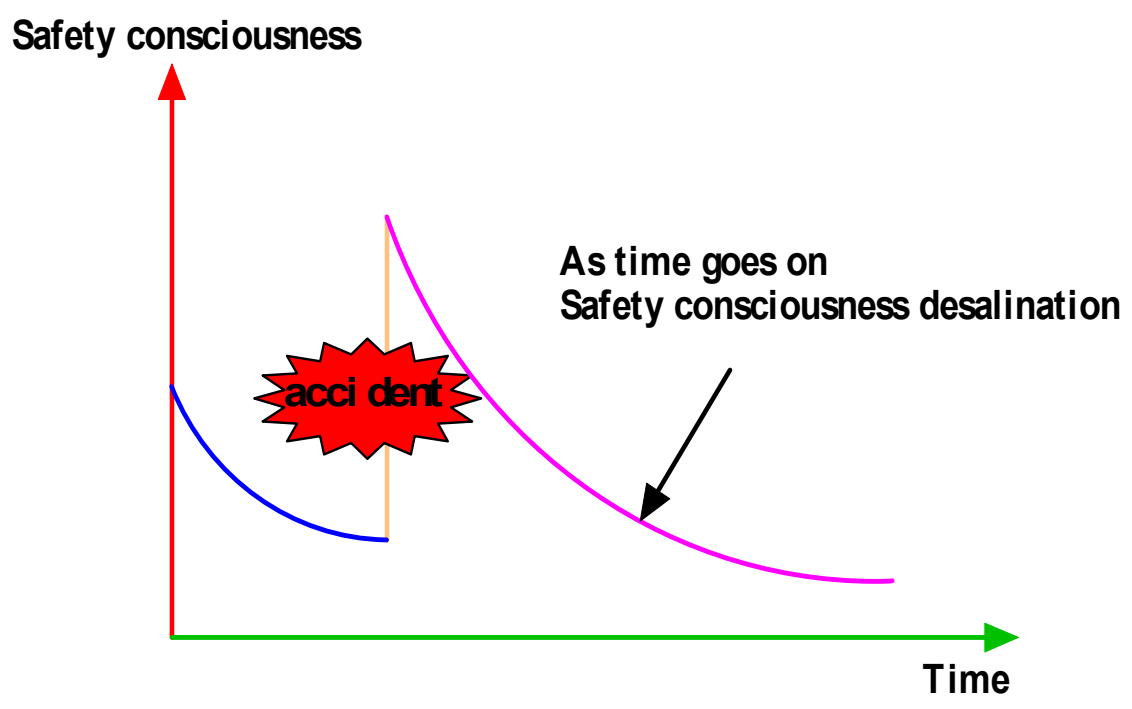

Fig. 1. Employee of safety consciousness and time relationship.

At the same time, due to the small scope of serious accident frequency will not be too high, It will make the staff produce the idea that is "unsafe behavior may not cause the accidents, unsafe behavior can improve the work efficiency". In addition, there is another important factor that is employees of risk cognition. In conventional practice, employees of risk in cognitive on one hand is to rely on their own in the process of operation risk know common sense, On the other hand is enterprise managers for enterprise of various kinds of activities of the risk of system analysis and understanding, and through different means told operators, such as shift-overlap before operation, safety identification tips, Into the factory education, etc. But because the employee safety consciousness, they lack the necessary risk cognitive common sense. This is the main causes of the unsafe behavior. Thus, it can come to the employees of safety cognitive mode (see fig 2). 


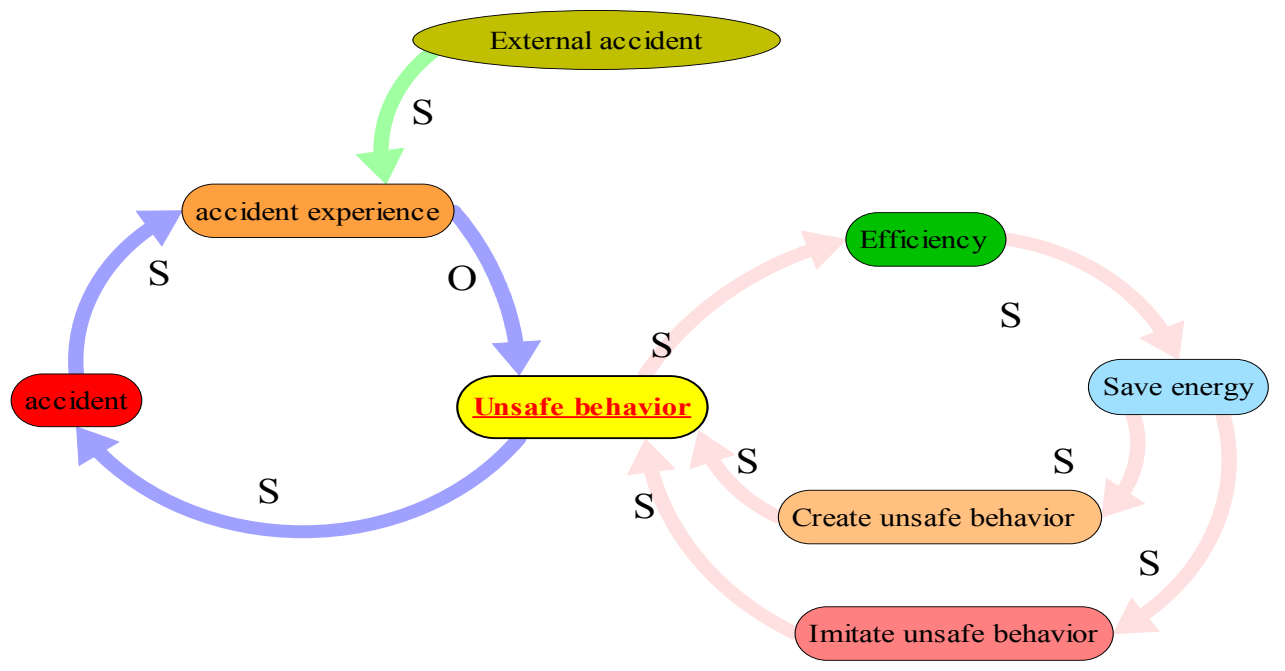

Note: $\mathrm{S}$ is Positive correlation; $\mathrm{O}$ is Negative correlation

Fig. 2. Employee of Cognitive model.

2. Managers of the cognitive concept generally

In the enterprise, the managers exist in the following cognition about unsafe behavior :

- Unsafe behavior is the key link, mechanical intergrity is the basis of production safety

- If unsafe behavior gradually spread, it will make the vicious cycle of production safety. If unsafe behavior gradually reduced, it will push the virtuous cycle of production safety.

From the view of the managers, unsafe behavior of accidents will increase enterprise's safety management of pressure and affect the normal operation of the enterprise, further influence enterprise overall efficiency. At the same time, under pressure in the business, some managers will have to take the measures put into lower safety, but if the safety input is reduced, it will affect the equipment of intrinsically safe and safety training, this will cause unsafe behavior and the unsafe condition of the increase. It will lead to the increase of the accidents and form the vicious circle.

On the contrary, if the managers take measures to reduce unsafe behavior and unsafe condition, it will lower accident rates. The managers can put the energy and resources into equipment of intrinsically safe and employee safety quality improvement. It will further enhance the enterprise the overall level of safety management. Thus, it can come to the managers of safety cognitive mode (see fig 3). 


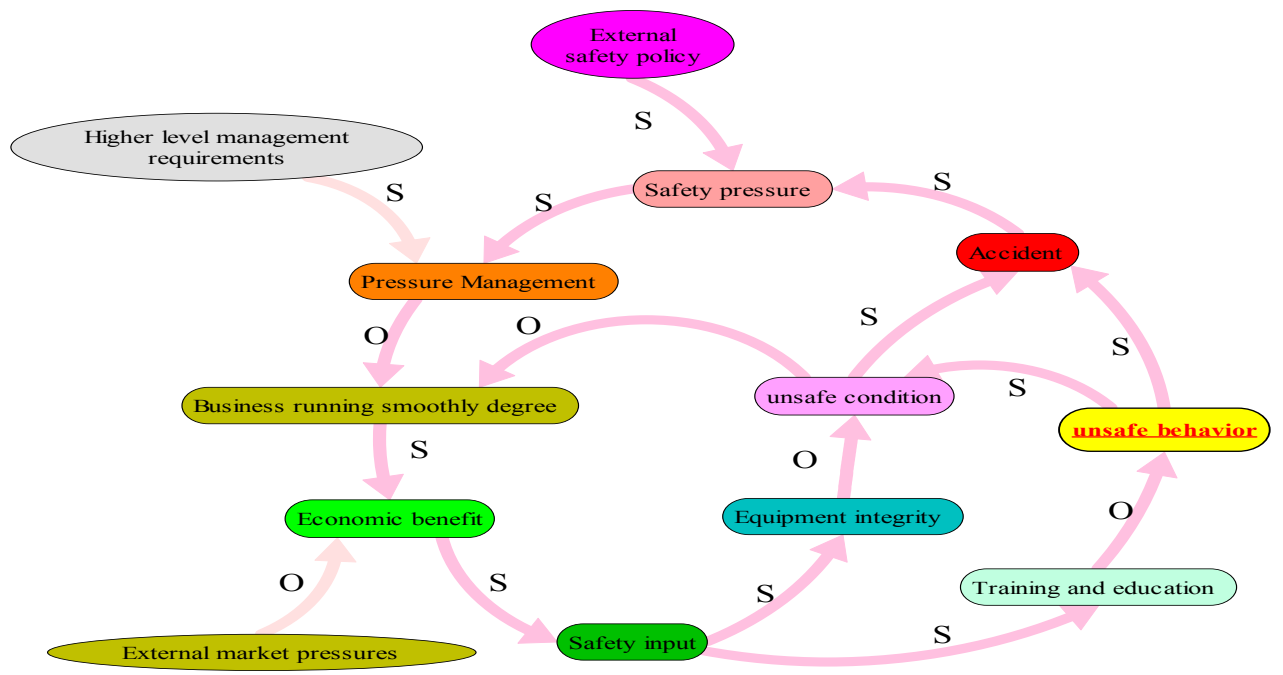

Fig. 3. Managers of Cognitive model.

\section{Recommend common safety cognitive concept}

Through the analysis of enterprise employees and managers of unsafe behavior cognition, and combined with the employees and managers of the safety cognitive model, it can come to the employees and managers of common safety cognitive concept. That is the uniform safety cognitive concept, see fig 4 .

The common safety the cognitive concept of idea lies in:

- Prevent accidents and avoid damage are our common goals and commitments.

- Strengthen communication, promote safety behavior and develop HSE cultural are to promote safe production of the benign circulation pry points.

- Pay attention to the draw lessons from the accident outside enterprises is the best way.

- Eliminate equipment safety problems and Improve device integrity level are the basis of production safety.

Safety needs the managers and employees involved in. The managers and employees follow the principle of uniform management and form the common perception mode. Eliminate unsafe behavior is the key to prevent accidents. Eliminate unsafe behavior is the enterprise safety development necessary means. Eliminate unsafe behavior is everyone's responsibility. Only in form the correct on the basis of common cognitive mode, the system of safety management can be enforced, the safety management measures can be truly carried out. Through the model the virtuous cycle of their own, it can improve the device of essence safety, it can strengthen and standardize the safety of the employees behavior. It will radically reduce or eliminate unsafe condition of object and the unsafe behavior of the people, so as to achieve the purpose of reducing and put an end to the accidents. 
We analysis the concept of the common safety cognitive purpose that is to through the HSE idea infusion, safety culture atmosphere build, formation and strengthen the correct cognition model, standard work behavior, find and eliminate unsafe behavior and unsafe condition. At the same time, it makes enterprise employees and managers know to eliminate unsafe behavior and unsafe condition. It not only need to the employees own safety consciousness and homework habit of ascension,but also need to enterprise managers in the construction of safety culture, safety input, etc to ascend, and take effective measures and means of management, to reduce the man-made accidents. It will promote the enterprise the safety operation level from the whole.

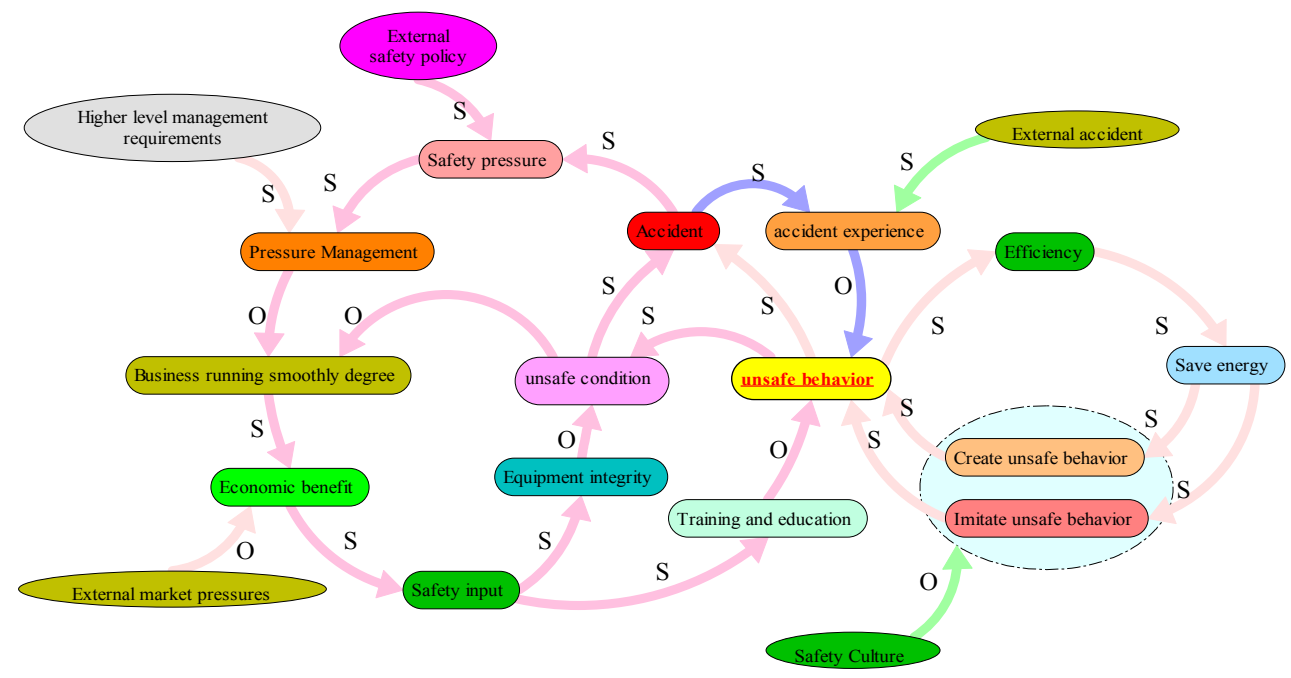

Fig. 4. Common cognitive model.

\section{Effective solution}

Through the common cognitive model that can be seen, in addition to model their internal circulation outside, the whole cycle graph of the external input have external safety policy, superior management requirements, external market pressure, external accidents and safety culture. In the five aspects, for enterprise in solving unsafe behavior of the effective input is only external accidents and safety culture. For external accidents, it's just a short accident education process, it can't form long-term input to reduce the enterprise employees's unsafebehavior. But safety culture as a stable and effective long-term input, the enterprise through the safety culture construction and propaganda, it can gradually reduce the incidence of enterprise unsafe behavior and effectively reduce the accident rates.

The construction of safety culture of the enterprise is a long process, in the process of how to find and correct the employees of unsafe behavior, to gradually regulate the employees of safety behavior is particularly important. In this respect the effective method is to implement behavior safety management tools. This paper introduced at present in SINOPEC widely applied behavior safety management tool - HSE observation card. 
HSE observation card is a method that is to encourage employees voluntarily observed the operating personnel behavior. Its purpose is to encourage safety behavior, stop and correct unsafe behavior. Through the effective communication, it can be to strengthen operation personnel to safety consciousness and standardize safety behavior. At the same time, it will see that the work environment and facilities and the use of tools, and found that and deal with unsafe condition of object, effectively avoid and reduce accident and the occurrence of injury.

\section{Conclusion}

If we will enhance safety culture and standardize employee safety behavior, it cannot leave the application of behavior-based safety management tools. The behavior-based safety management tools are an important means that is to effectively promote the safety culture of enterprise. At present, in SINOPEC comprehensive application of HSE observation tools, its core is to conduct field observation and analysis and communication, to interfere with the way or intervention, make people know the dangers of unsafe behavior, prevent and eliminate unsafe behavior.

Implementation of behavior safety management and correction employee in the work unsafe behavior, it is at home and abroad common practice in the industry. Through these tools and methods are to implement and promote, it can reduce the frequency of occurrence of employee unsafe behavior, thus it can avoid employees of unsafe behavior which led to the accident, and promote enterprise of safety performance.

\section{References}

Sun Ai-jun, LIU Mao.The Implementing Predicament of Behavior-based Safety Management Theory and Its Solution[J]. China Safety Science Journal, 2009,(09).

Xiu Jing-tao. Exploration and practice of behavior safety management[J]. Journal of Safety Science and Technology, 2008,(04).

Zhang Ya-wei; Wang Bing-jian.Theoretical foundation of three violation psychology in coal mine [J]. Shandong Coal Science and Technology, 2009,(03).

Sun Shu-ying. Unsafe behavior in furniture enterprise[J]. Journal of Safety Science and Technology, 2009,(01).

Cao Qing-ren. Study on the Cognitive Diversities between Managers and Workers in Controlling Unsafe Behavior[J]. China Safety Science Journal, 2007,(01).

Zhao En-qian. Case Analysis and Psychological Discussion on Behavior Safety [J].Petrochemical Safety Technology, 2006,(04).

Liang Li. An Analysis of Violation Behavior and Psychological Factors[J]. China Safety Science Journal, 2006,(08).

Lu Bao-he. Analysis and Control of Rule-Breaking Behavior[J]. China Safety Science Journal, 1997,(05).

Liu Yi-song. The Discuss of Unsafe Behavior in Safety Management[J]. West-china Exploration Engineering, 2005,(06).

Dai Licao; Engineer Zhang Li Huang Shudong. Analysis of Fundamental Causes of Manmade Errors in Complex Industrial System[J]. China Safety Science Journal, 2003,(11). 


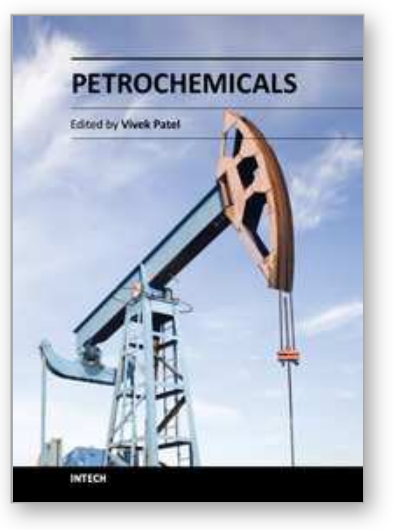

\author{
Petrochemicals \\ Edited by Dr Vivek Patel
}

ISBN 978-953-51-0411-7

Hard cover, 318 pages

Publisher InTech

Published online 28, March, 2012

Published in print edition March, 2012

The petrochemical industry is an important constituent in our pursuit of economic growth, employment generation and basic needs. It is a huge field that encompasses many commercial chemicals and polymers. This book is designed to help the reader, particularly students and researchers of petroleum science and engineering, understand the mechanics and techniques. The selection of topics addressed and the examples, tables and graphs used to illustrate them are governed, to a large extent, by the fact that this book is aimed primarily at the petroleum science and engineering technologist. This book is must-read material for students, engineers, and researchers working in the petrochemical and petroleum area. It gives a valuable and costeffective insight into the relevant mechanisms and chemical reactions. The book aims to be concise, selfexplanatory and informative.

\title{
How to reference
}

In order to correctly reference this scholarly work, feel free to copy and paste the following:

Mu Shan-Jun, Shi Hong-Xun, Wang Xiu-Xiang, Zhang Xiao-Hua and Bian Min (2012). Safety Cognitive Concept and Countermeasure Analysis for Petrochemical Industry, Petrochemicals, Dr Vivek Patel (Ed.), ISBN: 978-953-51-0411-7, InTech, Available from: http://www.intechopen.com/books/petrochemicals/safetycognitive-concept-of-research-and-countermeasure-analysis

\section{INTECH}

open science | open minds

\author{
InTech Europe \\ University Campus STeP Ri \\ Slavka Krautzeka 83/A \\ 51000 Rijeka, Croatia \\ Phone: +385 (51) 770447 \\ Fax: +385 (51) 686166 \\ www.intechopen.com
}

\author{
InTech China \\ Unit 405, Office Block, Hotel Equatorial Shanghai \\ No.65, Yan An Road (West), Shanghai, 200040, China \\ 中国上海市延安西路65号上海国际贵都大饭店办公楼405单元 \\ Phone: +86-21-62489820 \\ Fax: $+86-21-62489821$
}


(C) 2012 The Author(s). Licensee IntechOpen. This is an open access article distributed under the terms of the Creative Commons Attribution 3.0 License, which permits unrestricted use, distribution, and reproduction in any medium, provided the original work is properly cited. 